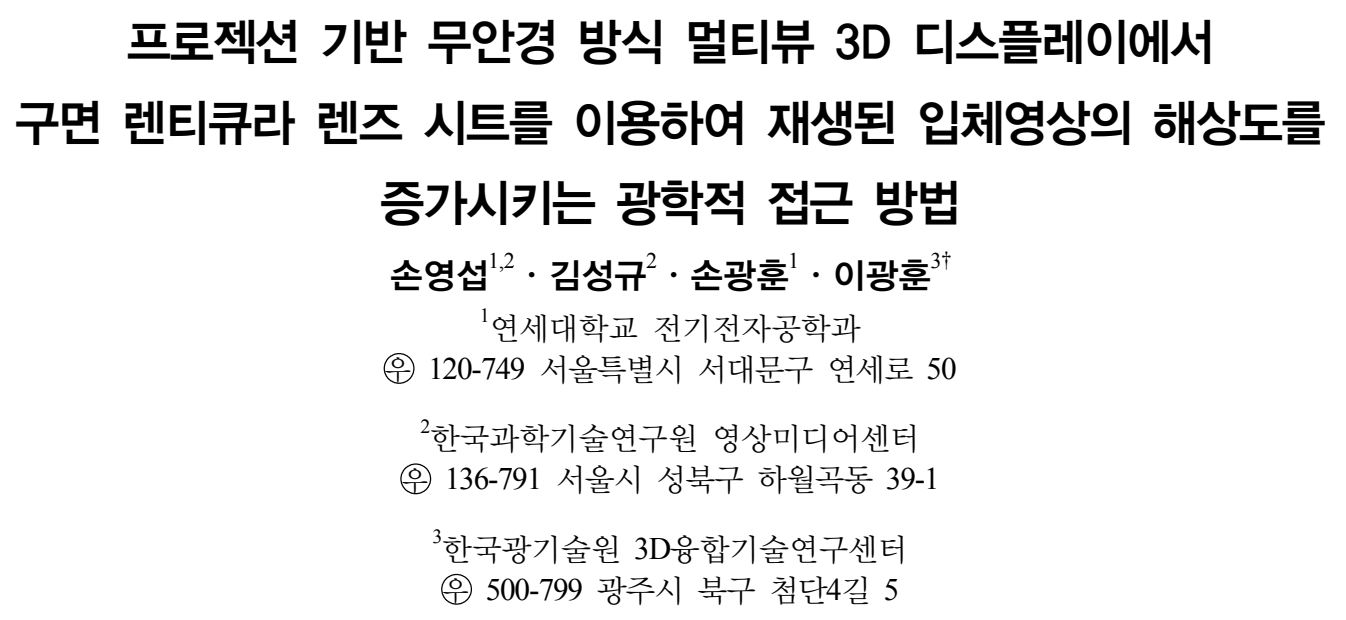

(2012년 6월 11일 받음, 2012년 7월 3일 수정본 받음, 2012년 7월 3일 게재 확정)

고정 화소수의 표시소자를 기반으로 하는 무안경 방식 다시점 $3 \mathrm{D}$ 디스플레이는 시점수 증가에 따른 입체영상 저해상도 문제를 안고 있다. 이를 해결하기 위하여, 본 논문은 프로젝션 기반의 무안경식 다시점 $3 \mathrm{D}$ 디스플레이 시스템에서 구면 형태의 상용 렌티큐라 렌즈시트를 사용하여 단위화소의 폭을 집속하고 광원수 증가에 따른 유효 해상도를 증가시켜 저해상도의 문제를 해결 하는 광학적 접근 방법을 제시하였다. 제시된 방법은 주어진 시스템환경에서 도출 가능한 주요 파라메터의 정의 및 이론적, 실험 적 결과를 통하여 축소 가능한 단위화소폭 및 확장 가능한 유효 해상도를 도출하는 수순으로 수행되었다. 결과적으로 $1.016 \mathrm{~mm}$ 의 단위화소폭을 기준으로 $25 \mathrm{LPI}$ 의 렌티큐라 렌즈 시트를 투과하였을 경우, 축소된 폭(Beam waist)은 $0.19 \mathrm{~mm}$, 확장 가능한 유효 해상도는 최대 5 배를 나타내었다. 이와 더불어, 초점심도(Depth of focus)는 $1.496 \mathrm{~mm}$ 로서 상용 렌티큐라 렌즈 시트의 두께 허용치 및 광학계 정렬 허용범위를 충분히 확보하였다.

\title{
Optical Approach for Increasing the Resolution of Displayed Multi-view Image from Projection Type of Auto-stereoscopic 3D Display System by Adopting a Commercial Spherical Lenticular Lens Sheet
}

\author{
Young-Sub Sohn ${ }^{1,2}$, Sung-Kyu Kim ${ }^{2}$, Kwanghoon Sohn ${ }^{1}$, and Kwang-Hoon Lee ${ }^{3 \dagger}$ \\ ${ }^{1}$ Department of Electrical and Electronic Engineering, Yonsei University, Seoul 120-749, Korea \\ ${ }^{2} 3 D-L a b$, IMRC, Korea Institute of Science and Technology, Seoul 136-791, Korea \\ ${ }^{3} 3 D$ Convergence Technology Research Center, Korea Photonics Technology Institute, Gwangju 500-779, Korea
}

(Received June 11, 2012; Revised manuscript July 3, 2012; Accepted July 3, 2012)

\begin{abstract}
Multi-view 3D displays based on a limited number of pixels have the problem that the stereo-scopic image has a low resolution because of increasing view number. To solve the problem of low resolution, we propose an optical approaching method that focuses the width of a unit pixel by using a commercial spherical shape lenticular lens sheet and increases the effective resolution by increasing the number of sources of light in the multi-view 3D display system based on projection type. The method was performed in such an order that several main derivable parameters were defined, and, through the theoretical and experimental result, the value of the contractible unit pixel width and the scalable effective resolution was derived in a given system environment. As a result, for the case that the ray of light from the projector transmitted the 25 LPI lenticular lens sheet which
\end{abstract}

${ }^{\dagger}$ E-mail: geniuspb@kopti.re.kr

Color versions of one or more of the figures in this paper are available online. 
has the pitch size $1.016 \mathrm{~mm}$, the focused unit pixel width was $0.19 \mathrm{~mm}$ and the scalable effective resolution was, at most, 5 times wider than the original one. In addition, the range of depth of focus was $1.496 \mathrm{~mm}$, which shows us the range of thickness tolerances of commercial spherical shape lenticular lens sheet and sufficient optical alignment tolerances.

Keywords: Beam waist, DOF, Auto-stereoscopic multi-view 3D display, Lenticular lens sheet, Beam propagation property OCIS codes: (080.0080) Geometric optics; (120.2040) Displays; (120.4640) Optical instruments

\section{Introduction}

무안경 방식의 다시점 $3 \mathrm{D}$ 디스플레이는 안경식과 달리, 다 수의 시점영상을 이용하여 관찰자에게 운동시차를 유발하고, 자연스런 입체시를 제공하는 장점이 있다. 무안경 방식에서 입체시 구현에 사용되는 대표적인 시역형성 광학계로는 시 차장벽 플레이트 또는 렌티큐라 렌즈 시트가 있다. 이러한 광학계는 시점 수에 따른 시역을 분리하고, 분리된 시점영상 의 단위쌍 조합으로 관찰위치에 따른 다시점의 입체시를 제 공한다 ${ }^{[1-2]}$. 두 광학계의 장점은 시스템의 구조가 비교적 간 단하다는 것을 들 수 있다. 그러나 시차장벽 방식은 제작이 쉬우나 밝기가 저하의 단점이 있고, 렌티큐라 방식은 밝기는 좋으나 대형화가 어렵고, 광학적 특성을 제어하기 위한 주문 제작 시 비용이 많이 든다는 단점이 있다. 재생된 입체시의 화질과 관련된 여러 구속조건들이 있는데, 특히 시역간 크로 스톡 문제 및 제한된 해상도를 시점 수만큼 나누어 쓰는 저 해상도의 문제가 가장 대표적이다 ${ }^{[1-2]}$. 그러나 시역간 크로스 톡 문제에 대한 연구는 비교적 많은 반면, 저해상도 문제에 대한 연구는 다소 미비하다.

시점수 증가에 따른 해상도 저하 문제는 각 시점영상의 최 대 해상도 및 시역형성 광학계의 특성에 크게 좌우된다. 최 적 관찰위치에서 고해상도의 밝고 명확한 입체영상을 시청 하기 위해서는 비구면 형태의 렌티큐라 렌즈 시트를 시역광 학계로 사용하고, 다수의 광원을 이용하는 프로젝션 기반의 무안경 $3 \mathrm{D}$ 디스플레이 시스템이 적절하다. 왜냐하면 다수의 광원은 각 시점영상의 해상도를 증가시키며, 비구면 렌티큐 라 렌즈 시트는 수차가 최소화된 명확한 상을 제공하기 때문 이다. 그러나 앞서 언급하였듯이, 비구면 형태의 렌티큐라 렌즈 시트는 제작비용이 높고 광학적 특성을 제어하기가 쉽 지 않다. 이에 본 논문은 기존 구면 형태의 상용 렌티큐라 렌즈 시트를 사용하여 앞서 언급된 문제들을 해결하고, 나아 가 비구면 형태의 특성에 준 할 수 있는 광학적 접근 방법을 모색하는데 있다. 연구 방법으로는 프로젝터로부터 투사되는 광원의 특성과 상용 렌티큐라 렌즈 시트의 광학적 특성과의 정성적 관계를 유도하고, 이를 정량화 함으로서, 일반램프를 사용하는 프로젝터의 최대 가용 수 및 이로부터 확장 가능한 시점영상의 최대 해상도를 정의하였다. 결과적으로 해상도 증가를 위한 가용 광원 수는 광원의 광질, 투사거리, 입사각 그리고 구면 렌티큐라 렌즈릿의 굴절률, 분산치, 피치 등에 의해 결정된다. 본 방법은 구성은 일반램프를 광원으로 사용 하는 프로젝터 부와, 투사거리에 비례하는 광원의 단위화소
폭과 동일한 피치를 갖는 렌티큐라 렌즈 시트 부, 렌티큐라 렌즈 시트를 투과한 광원을 산란시켜 시야각을 확대시키는 확산시트 부로 이루어져 있다.

\section{Theory}

프로젝터의 최종 렌즈면으로부터 출사된 단위화소의 영상 중심은 렌티큐라 렌즈 시트를 구성하고 있는 단일렌즈인 렌 티릿(lentilet)의 구면으로 사영된다. 사영된 단위화소 영상은 snell's law에 의해 해당 렌티릿 굴절면의 법선과 이루는 입 사각으로 입사하여 경계면에서 굴절하고 매질내로 투과한다 ${ }^{[3-4]}$. Ray optics의 관점에서 단위화소영상은 단위면적내 균일 한 분포의 광선다발로 생각할 수 있다. 따라서 렌티릿을 투 과한 단위화소 영상은, 결과적으로, 구면에 의해 발생한 수 차로 인하여 상면에서 한점으로 결상되지 않고, 상면과 평행 한 횡방향의 광폭을 갖게 된다. 이때의 폭을 렌티릿의 특성에 의해 집속된 단위화소영상의 광폭이라 할 수 있으며, 집속된 빔의 중심위치는 광폭이 최소가 되는 위치가 된다. 집속된 광 폭은 상면과 수직한 방향에서의 Rayleigh range를 만족하는 $\mathrm{DOF}$ (초점심도, Depth Of Focus) 범위를 갖게 된다. 상용 구 면 렌티큐라 렌즈 시트로 구면수차를 제어한 경우는 비구면 으로 구면수차를 제어한 경우보다 $\mathrm{DOF}$ 의 범위가 길다. 이러 한 효과는 렌티큐라 렌즈 시트 두께의 제작공차 및 비축 입 사하는 단위화소 영상의 집속면의 위치에 대한 허용치를 늘 려준다. 따라서 프로젝션 기반의 $3 \mathrm{D}$ 디스플레이 시스템에서

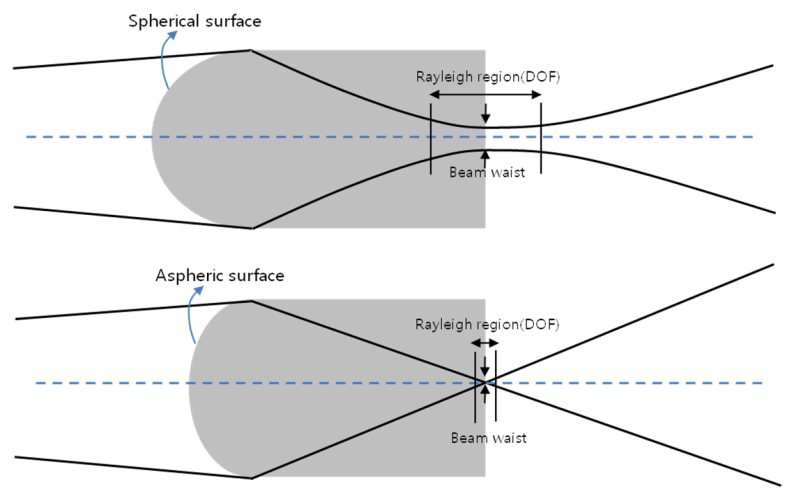

FIG. 1. The concept diagram of the beam waist and DOF that transmitted aspherical lens and spherical lens. Since a range of the beam waist and DOF in spherical lens is wider than in aspherical lens, it has an advantage of increased thickness tolerance of lenticular lens relatively, rather than the case of the aspherical lens. 
는 대형화에 따른 광학계의 휨 및 제작공차 등을 고려할 때, 상용화된 구면 렌티큐라 렌즈 시트가 비구면의 경우보다 더 욱 적절할 수 있다. 그림 1 은 구면 및 비구면의 렌티릿을 지 나 집속된 단위화소들의 광폭 및 $\mathrm{DOF}$ 의 개념도를 나타낸다.

\subsection{On-axis Incoming Rays: Defining Beam Waist \& DOF}

광폭의 결정은 일반적으로 Gaussian beam profile의 파장 lambda를 갖는 레이져 광(TEM00)이 볼록렌즈를 지나 초점 거리에서 형성되는 beam waist를 결정하는 방법으로 유도할 수 있다 ${ }^{[5]}$. 식 (1)은 일반적인 레이져 광원(Gaussian beam profile)을 사용한 평행광이 볼록렌즈와 광축정렬(On-axis) 후 입사하였을 때 렌즈를 투과한 광이 초점면에서 결상된 광폭 (Beam waist)을 나타내는 식이다. 이 때 M은 Beam propagation property를 나타내며, TEM00모드의 경우 $M=1$ 이다 $^{[6]}$. 여기 서 $w_{0}$ 는 집속된 광폭의 반치를 나타낸다. $\lambda$ 는 사용한 광원의 파장을 나타내고, $\mathrm{EFL}$ 은 Effective Focal Length를, $\mathrm{EPD}$ 는 Entrance Pupil Diameter로 렌티릿의 피치 $(P)$ 를 나타낸다.

$$
2 w_{0}=\frac{4 \lambda}{\pi} \frac{E F L}{E P D} M^{2}
$$

프로젝터의 경우 광원이 레이져가 아닌 일반 램프광원이므 로 정확한 광폭의 결정은 반드시 광원의 $M$ 이 반영되어야 한 다. 왜냐하면 $M$ 은 광원의 광질을 나타내는 척도이기 때문이 다 ${ }^{[7]}$. 식 (1)은 렌즈 매질의 분산특성을 대변하지 못한다. 따 라서 실제의 경우와 비슷한 조건을 구성하기 위해서는 $M$ 뿐 만 아니라 렌티매질의 분산값 $($ Abbe number $=V$ )이 반영되 어야 한다. 왜냐하면 $V$ 는 매질의 광분산특성을 대변하는 척 도이기 때문이다. 뿐만 아니라, 프로젝터는 유한거리의 투사 거리에 위치하므로 식 (1)의 $\mathrm{EFL}$ 은 상거리 $\left(S_{i}\right)$ 가 되어야한다. 따라서 집속된 빔 폭은 $M, V, S_{i}$ 그리고 $P$ 와 관계하는 함수 가 된다. 그림 2는 이를 나타내는 모식도이다.

식 (1)을 일반광원 및 렌즈매질의 특성과 관계된 일반화 식으로 확장하기 위하여 다음과 같은 수학적 분석과정을 수 행하였다. 식 (2)는 단일렌즈에 의한 분산지수인 Abbe number $(V)$ 의 수학적 정의를 나타낸 식이다. 여기서 $n_{F}, n_{d}, n_{C}$ 는 각 각 파장에 따른 상대 굴절률을 나타내며, 파장의 길이는 486 $\mathrm{nm}, 588 \mathrm{~nm}, 656 \mathrm{~nm}$ 이다.

$$
V=\frac{n_{d}-1}{n_{F}-n_{C}}
$$

식 (3)은 투사거리 $\left(S_{o}\right)$ 와 초점거리(EFL)에 따른 $S_{i}$ 를 나타 내는 식이다. 여기서 렌티큐라렌즈는 Convex-Planar 타입이 므로 곡률면의 곡률반경 $R$ 만 고려하였고, 상면은 렌티큐라 매질 내에서 위치한다고 가정하였다. $n_{l}, n_{m}$ 은 각각 렌티큐라 렌즈 시트 매질의 굴절률과 공기매질의 상수굴절률 나타낸다.

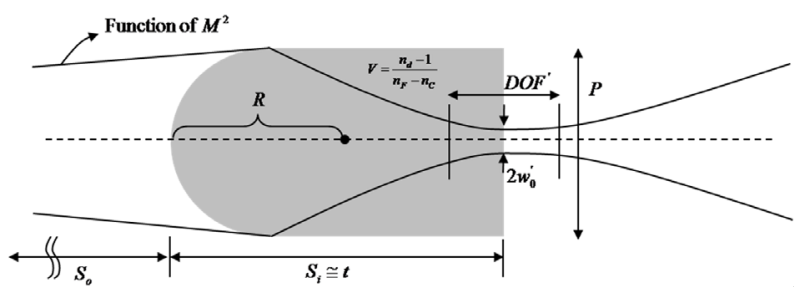

FIG. 2. The explanation of the beam waist and range of DOF at the focused plane, in case of the unit pixel image which has the beam propagation property factor $M$ being transmitted through the optical axis from the projector located at the object distance $S_{i}$, when it focused by passing through the lenticular lens with the variance $V$.

$$
\begin{aligned}
S_{i} & =\frac{E F L \cdot S_{o}}{S_{o}-E F L} \\
& =\frac{\left(\frac{n_{l} R}{\left(n_{l}-n_{m}\right)}\right) \cdot S_{o}}{S_{o}-\left(\frac{n_{l} R}{\left(n_{l}-n_{m}\right)}\right)}
\end{aligned}
$$

식 (4)는 식 (2)와 식 (3)을 연립하여 나타낸 식이며, 물리 적인 의미는 분산지수와 관계하는 상거리를 나타낸다. 여기 서 각 매질의 경계면을 기준으로 해당 매질의 상수 굴절률은 분산지수와의 관계성을 보이기 위하여 $n_{l}=n_{d}, n_{m}=1$ 로 치환 하여 적용하였다.

$$
S_{i}=\frac{n_{d} R S_{o}}{S_{o} V\left(n_{F}-n_{C}\right)-n_{d} R}
$$

식 (2) (4)의 전개로부터, 일반광원을 사용하는 투사광학계 기반에서 단위영상이 렌티릿을 지나 상면에서 집속되어 최 소 광폭 $\left(2_{w}^{\prime}\right)$ )을 나타내는 일반화를 식 (5)에 나타내었다. 기 준파장은 $\lambda_{d}$ 를 적용하였다.

$$
2 w_{o}^{\prime}=\frac{4 \lambda_{d}}{\pi} \frac{1}{P}\left(\frac{n_{d} R S_{o}}{S_{o} V\left(n_{F}-n_{C}\right)-n_{d} R}\right) M^{2}
$$

렌티릿을 지나 집속된 광원의 광폭은 단위 렌티릿 당 할당 되는 시점영상 수를 결정하는 요소이고, 결과적으로 프로젝 션 타입의 3D 디스플레이 시스템에서 해상도 저하 없이 사 용 가능한 다시점 영상수를 결정하는 핵심 구속조건이 된다. 따라서 프로젝터의 특성(광질, 투사거리) 및 렌티큐라 렌즈 의 광학적 특성(굴절률, 피치, 두께, 분산지수, 곡률반경)은 렌티큐라 기반의 프로젝션 $3 \mathrm{D}$ 디스플레이 시스템에서 반드 시 고려해야 할 중요인자이다. 일반 램프타입의 프로젝터 광 원은 레이져 광원보다 광질이 낮고, 렌즈를 투과하여 집속된 광폭은 넓다. 식 (5)로부터, 사용하고자 하는 렌티릿의 피치 내에 집속할 수 있는 다시점 영상의 수는 단위 피치당 집속 
된 광폭으로 정의될 수 있다. 식 (6)은 이를 나타내는 수학적 정의이고, $N_{\text {views }}$ 는 단위 피치 내에 집속될 수 있는 다시점 영 상 수를 의미한다.

$$
N_{\text {views }}=\text { Round }\left[\frac{P}{2 w_{o}^{\prime}}\right]
$$

이와 더불어 중요한 구속조건은 식 (5)에 의해 정의된 광 폭이 상면과 수직한 종방향에서의 Rayleigh range를 만족하 는 DOF값이다. 이는 식 (4)의 $S_{i}$ 가 고려된 렌티큐라 렌즈 시 트의 두께 $(t)$ 를 정의하는 중요요소가 된다. 왜냐하면 $\mathrm{DOF}$ 의 범위가 클수록 렌티큐라 렌즈 시트 두께의 허용범위가 넓어 지기 때문이다. 이는 상용렌티큐라 렌즈 시트를 선택할 시 두 께에 대한 허용오차를 줄 수 있는 중요 요소가 된다. 식 (7)은 식 (5)에서 정의된 광폭에 대한 $\mathrm{DOF}$ 값(DOF')을 나타낸다.

$$
\begin{aligned}
D O F^{\prime} & =2 w_{o}^{\prime}\left(\frac{1}{P} \frac{n_{d} R S_{o}}{S_{o} V\left(n_{F}-n_{C}\right)-n_{d} R}\right) \\
& =\frac{4 \lambda_{d}}{\pi}\left(\frac{1}{P}\left(\frac{n_{d} R S_{o}}{S_{o} V\left(n_{F}-n_{C}\right)-n_{d} R}\right)\right)^{2} M^{2}
\end{aligned}
$$

식 (8)은 $S_{i}$ 를 기준으로 식 (7)의 값으로부터 사용 가능한 렌티큐라 렌즈 시트 두께 $t$ 의 허용범위를 나타낸다.

$$
\left(S_{i}-\frac{D O F^{\prime}}{2}\right) \leq t \leq\left(S_{i}+\frac{D O F^{\prime}}{2}\right)
$$

상면과 수직한 종방향에서의 $\mathrm{DOF}$ 는 레이져 광원의 경우 보다 증가하므로 동일 렌티큐라 렌즈를 사용할 시, 투사거리 의 가용범위가 넓어지고, 렌티큐라 렌즈 시트 두께의 제작공 차값은 여유로워지는 장점을 갖는다.

\subsection{Off-axis Incoming Rays}

프로젝터로부터 사영되는 단위화소영상이 렌티릿의 광축에 서 벗어나 비축입사할 경우, 상면에서 집속된 광폭은 광축입사 한 경우 보다 증가한다. 그림 3은 이를 나타내는 모식도 이다.

그림 3에서 알 수 있듯이, 각 단위화소의 영상이 화면외각

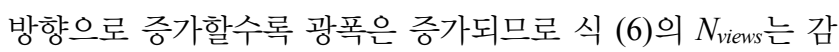
소한다. 따라서 비축입사에 대한 광폭( $2 w^{\prime}{ }_{0}$ off $)$ 은 식 (9)로 재 정의될 수 있다. 여기서 $\theta_{t}$ 는 렌티릿의 vertex에서 접선에 수 직한 법선과 이루는 입사각 $\left(\theta_{i}\right)$ 에 대한 투과각을 나타낸다. 따라서 $\theta_{t}$ 는 snell's law에 의해 입사각 $\theta_{i}$ 의 함수로 표현이 가능하다.

$$
2 w_{o_{-} \text {off }}^{\prime}=\frac{2 w_{o}^{\prime}}{\cos \theta_{t}}=\frac{2 w_{o}^{\prime}}{\cos \left[\sin ^{-1}\left[\frac{1}{n_{d}} \sin \theta_{i}\right]\right]}
$$

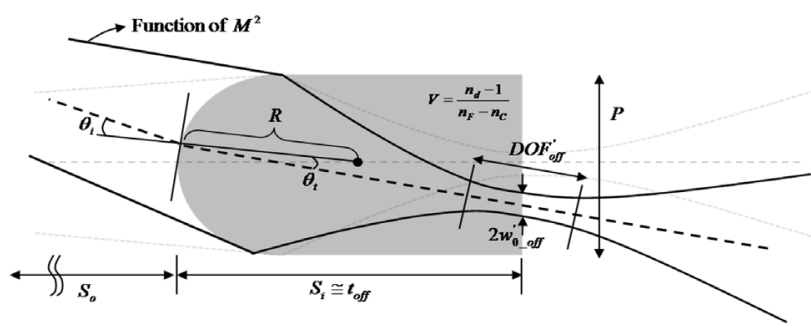

FIG. 3. The explanation of the beam waist and range of DOF at the focused plane, in case of same environments as figure2, except that the unit pixel image is transmitted with angle $\theta_{t}$ and $\theta_{t}$ is not zero.

식 (9)의 $\theta_{i}$ 를 투사거리 $\left(S_{o}\right)$ 와 해당 단위영상의 렌티릿의 중심과의 관계로 나타내면 식 (10)과 같다. 여기서 screen은 투사거리 $S_{o}$ 면에서 사영된 프로젝터 영상의 수평방향의 총 길이를 나타낸다. $N$ 은 단위 프로젝터의 해상도를 나타낸다. $i$ 는 해당 단위영상의 픽셀넘버를 나타내고, 범위는 1 부터 최 대 해상도까지이다. 따라서 입사각 $\theta_{i}$ 는 half screen의 위치를 기준으로 -/+ 의 비축 입사각을 갖는다.

$$
2 w_{o_{-} \text {off }}^{\prime}=\frac{2 w_{o}^{\prime}}{\cos \left[\sin ^{-1}\left[\frac{1}{n_{d}} \sin \left[\tan ^{-1}\left[\frac{\left(\frac{\text { screen }}{N}(i-1)+\frac{(P-\text { screen })}{2}\right)}{S_{o}}\right]\right]\right]\right]}
$$

식 (10)에 의해 식 (6), (7), (8)은 식 (11), (12), (13)으로 일 반화된다. 각 식에서 표기된 밑지수 off는 일반화식을 의미 한다.

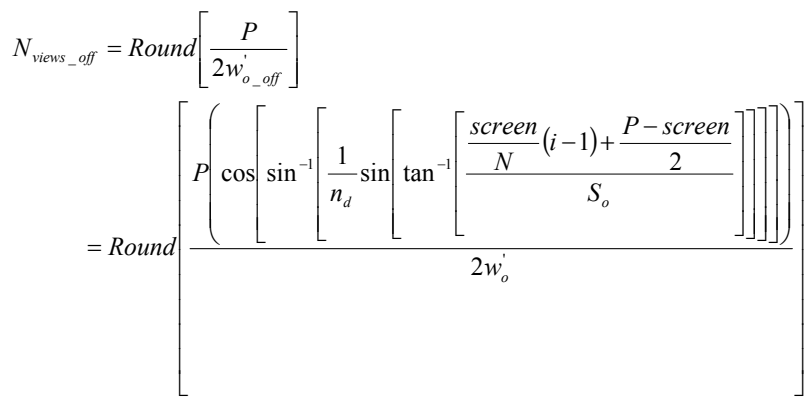

(11)

$$
\begin{aligned}
D O F_{\text {off }}^{\prime}= & 2 w_{o_{-} \text {off }}^{\prime}\left(\frac{1}{P} \frac{n_{d} R S_{o}}{S_{o} V\left(n_{F}-n_{C}\right)-n_{d} R}\right) \\
= & \frac{2 w_{o}^{\prime}\left(\frac{1}{P} \frac{n_{d} R S_{o}}{S_{o} V\left(n_{F}-n_{C}\right)-n_{d} R}\right)}{\cos \left[\sin ^{-1}\left[\frac{1}{n_{d}} \sin \left[\tan ^{-1}\left[\frac{\left(\frac{\text { screen }}{N}(i-1)+\frac{(P-\text { screen })}{2}\right)}{S_{o}}\right]\right]\right]\right]}
\end{aligned}
$$




$$
\left(S_{i}-\frac{D O F_{\text {off }}^{\prime}}{2}\right) \leq t_{o f f} \leq\left(S_{i}+\frac{D O F_{o f f}^{\prime}}{2}\right)
$$

\section{EXPERIMENT \& RESULT}

프로젝션 3D 디스플레이 시스템에서, 광원폭의 축소에 따 른 시점영상의 해상도 증가를 검증하기 위하여 다음과 같은 실험을 수행하였다. 실험에 사용된 프로젝터는 EPSON TW4500 모델이며, 해상도는 Full $\mathrm{HD}(1920 X 1080)$ 를 지원한다. 프로 젝터로부터 스크린까지의 투사거리 $S_{o}$ 는 $2,460 \mathrm{~mm}$ 이며, 스 크린에 결상된 1 차 광원의 폭은 $P=1.016 \mathrm{~mm}$ 이다. 2차 광원 을 형성하기 위하여 렌티큐라 렌즈 시트가 사용되었으며, 광 학적 특성은 다음과 같다. 렌티큐라 렌즈시트는 수평방향의 굴절능을 갖는 Cylinderical 형상의 Convex-Planar 타입이다. 재질은 PET 이며, 방향은 렌티릿의 굴절면이 프로젝터를 향 하도록 정렬하였다. 렌티큐라 렌즈 시트의 크기는 가로 5"
크기이며, 렌티릿 피치는 25 LPI로서 인치당 25 개(Line per inch - LPI)의 렌티릿으로 구성되어 있다. 렌티큐라 렌즈 시 트의 두께는 $t=3.63 \mathrm{~mm}$ 이고, 렌티릿의 곡률면상에 있는 Vertex로부터 평행한 면까지의 수직거리이다. 렌티릿의 곡률 반경은 $R=1.484 \mathrm{~mm}$ 이고, 매질의 분산값은 $\mathrm{V}=30.99$ 이다. 대표파장은 $\lambda_{F}=486 \mathrm{~nm}, \lambda_{d}=588 \mathrm{~nm}, \lambda_{C}=656 \mathrm{~nm}$ 로 정의 하였으며, 이에 따른 상대굴절률은 각각 $n_{F}=1.6050, n_{d}=$ $1.5915, n_{C}=1.5859$ 이다. Beam propagation property $(M)$ 는 프로 젝터로부터 사영된 광원이 투사거리 $S_{o}$ 에 위치한 렌티큐라 렌즈 시트를 투과하였을 시 측정된 광폭을 유도하여 정의될 수 있다. 실험을 통하여 측정된 광폭은 $2 w^{\prime}{ }_{0}$ off $=0.19 \mathrm{~mm}$ 이 고, 이 값은 $\theta_{i}=0$ 인 스크린의 중심 화소 $(i=960)$ 가 투사된 경우이다. 이를 식 (5)에 대입하여 획득한 $M$ 값은 11.35 이다. 표 1은 실험에 사용된 렌티큐라 렌즈 시트 및 렌티릿 그리고 광원에 대한 광학적 특성을 나타낸 표이다.

그림 4는 실험에 사용된 렌티큐라 렌즈의 단면 및 프로젝

TABLE 1. The optical property table of lenticular lens sheet, lenti-lit and light source used in the experiment

\begin{tabular}{rrr}
\hline \hline \multicolumn{1}{c}{ Properties } & Lenticular lens sheet & Lenticular lenslet \\
\hline Material & PET & \\
Projectiondistance $\left(\mathrm{S}_{\mathrm{o}}\right)[\mathrm{mm}]$ & 2,460 & \\
Size $[\mathrm{Inch}]$ & 5 & \\
LPI & 25 & \\
Type & Convex-Planar & \\
\hline Curvature Radius $[\mathrm{mm}]$ & & 1.4840 \\
Thickness $(\mathrm{t})[\mathrm{mm}]$ & & 3.6300 \\
$\mathrm{n}_{\mathrm{F}}$ & & 1.6050 \\
$\mathrm{n}_{\mathrm{d}}$ & & 1.5915 \\
$\mathrm{n}_{\mathrm{C}}$ & & 1.5859 \\
Abbe number $(\mathrm{V})$ & & 30.990 \\
\hline
\end{tabular}

Beam Propagation Property $\left(\mathrm{M} @ \lambda_{d}\right)$

$\mathrm{DOF}[\mathrm{mm}]$

Permitted thickness $(\mathrm{max} / \mathrm{min})[\mathrm{mm}]$

11.35

1.496

$4.746 / 3.251$

0.19

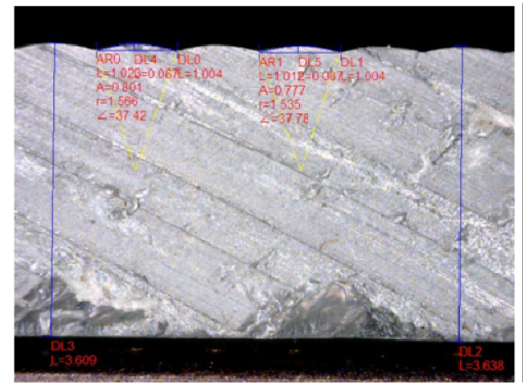

(a)

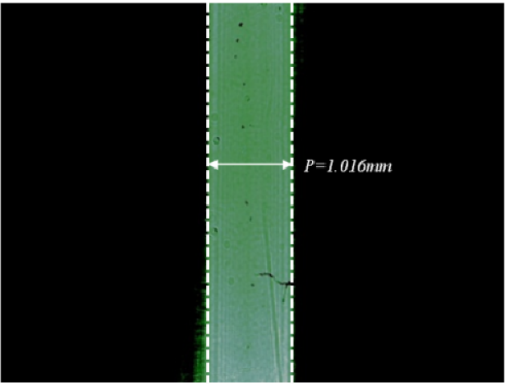

(b)

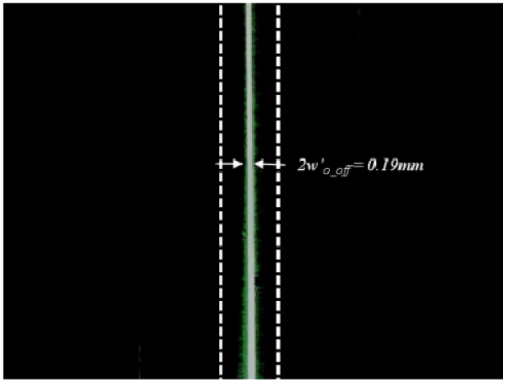

(c)

FIG. 4. (a) Cross-section of 25 LPI lenticular lens sheet used in the experiment. (b) The beam waist of the first order unit pixel light source $(P=1.016 \mathrm{~mm})$, measured at projection distance $S_{o}=2,460 \mathrm{~mm}$. (c) The reduced beam waist of the second order unit pixel light source focused by 25LPI lenticular lens $\left(2 w^{\prime}{ }_{0}\right.$ off $\left.=0.19 \mathrm{~mm}\right)$. 

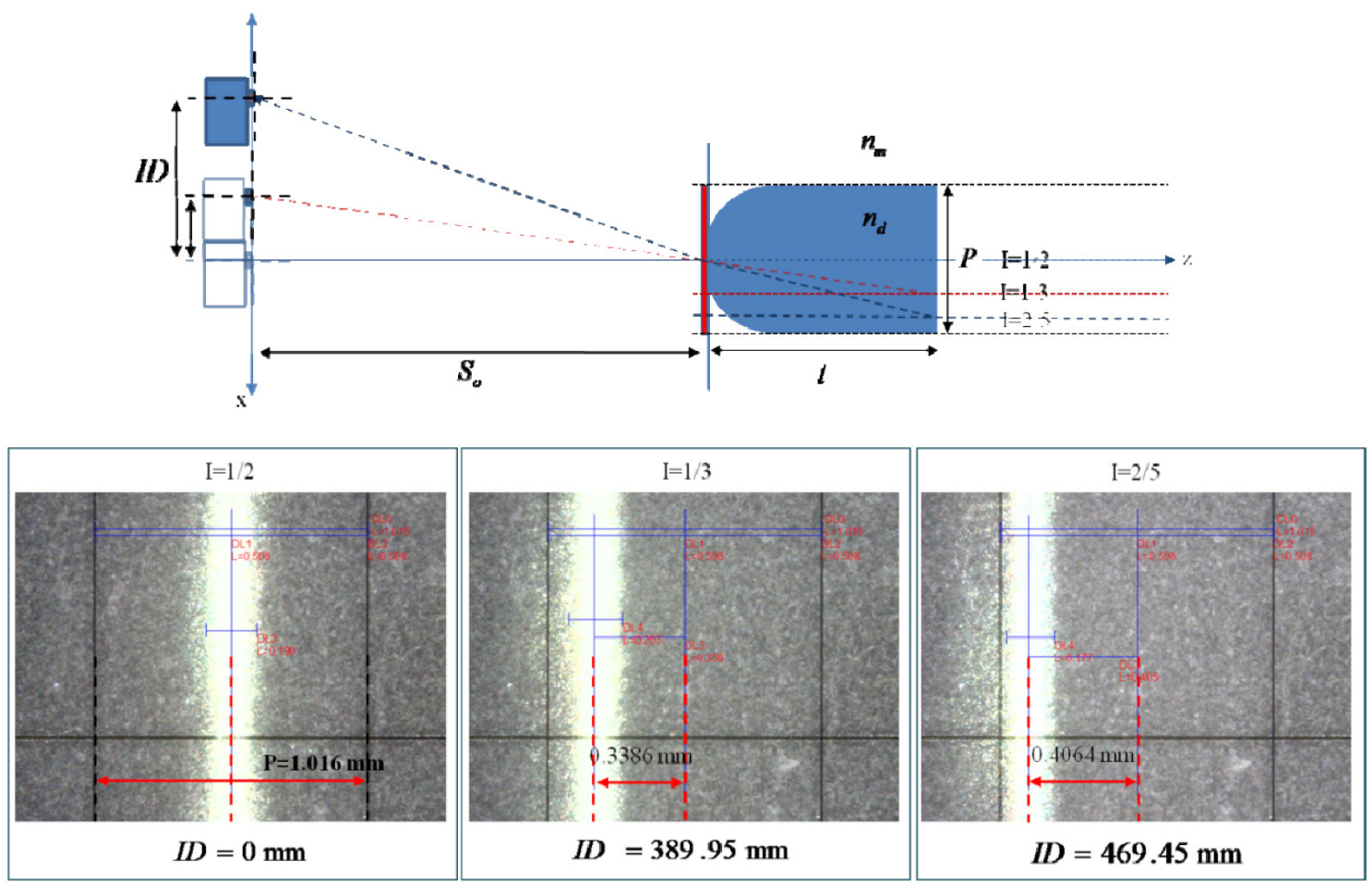

FIG. 5. Picture on the top represents the relation between uniform interval condition of second order light source and center-to-center distance of projector lenses, according to the number of projectors. Picture on the bottom represents the actual image of measuring center position of second order light source satisfying the condition that $\mathrm{I}=1 / 2, \mathrm{I}=1 / 3, \mathrm{I}=1 / 5$, in the case of $N_{\text {views }}$ being $1,3,5$ each. A displacement of the center position of the lenticular lens above are $0 \mathrm{~mm}, 0.3386 \mathrm{~mm}, 0.4064 \mathrm{~mm}$, and outermost center-to-center distance of projector lenses are 0mm, $389.95 \mathrm{~mm}, 469.45 \mathrm{~mm}$.

터로부터 사영된 광원이 렌티릿을 투과하여 축소된 광폭을 나타낸다. 본 논문에서 사용한 시스템의 경우, 사용된 25 LPI의 렌티릿 피치를 기준으로 가용할 수 있는 최대 프로젝 터 대수는 식 (4)에 의해 최대 $N_{\text {views }}=5$ 가 된다. 따라서 시점 영상의 해상도를 5 배 증가시킬 수 있다. 각 프로젝터의 동일 화소번호에 해당하는 단위화소영상을 해당 렌티릿에 사영시 킬 경우, 렌티릿을 투과하여 확산판 상에 집속된 각 2차 광 원들은 렌티릿의 피치 범위 내에서 각기 다른 위치를 갖는 다. 이 때 각 2 차 광원의 중심간 거리는 등간을 만족하고 연 속형태이어야 한다. 왜냐하면, 관찰면에서 형성된 이들의 시 역은 반드시 연속이어야만 관찰자 위치변화에 따른 연속적 인 운동시차의 제공이 가능하기 때문이다. 이를 위하여 프로 젝터 대수에 따른 각 2차 광원의 중심간 등간조건(I)과 투사 거리 $\left(S_{o}\right)$ 에 위치한 프로젝터의 투사렌즈 중심간 최외각 간격 (ID)과의 관계를 정량화 하였다. 식 (14)는 이에 대한 수학적 관계식을 나타낸다. 사용된 변수들의 정의는 다음과 같다. 등간조건 I는 $N_{\text {views }}=1,3,5$ 일 경우, 각각 $1 / 2,1 / 3,2 / 5$ 와 대응 한다. $n_{d}$ 는 $\lambda_{d}(588 \mathrm{~nm})$ 에 대한 렌티릿의 굴절률(1.599)을, $\mathrm{nm}$ 은 공기 굴절률(1)을, $\mathrm{P}$ 는 렌티릿의 피치 $(1.016 \mathrm{~mm})$ 를, $S_{o}$ 는 영상 투사거리 $(2,640 \mathrm{~mm})$ 를, $t$ 는 렌티큐라 렌즈 시트의 두께 (3.63 mm)를 나타낸다. 그림 5는 $N_{\text {views }}=1,3,5$ 일 경우, 각 프로젝터의 투사렌즈 중심간 위치에 대한 2 차 광원의 중심 위치를 측정한 결과를 나타낸다.

$$
I D=S_{o} \cdot \tan \left[\sin ^{-1}\left[\left(\frac{n_{d}}{n_{m}}\right) \sin \left[\tan ^{-1}\left(\frac{I \cdot P}{t}\right)\right]\right]\right]
$$

$\mathrm{I}=1 / 2,1 / 3,2 / 5$ 인 경우, 2 차 광원의 중심위치는 렌티릿의 중심을 기준으로 각각 $0 \mathrm{~mm}, 0.3386 \mathrm{~mm}, 0.4064 \mathrm{~mm}$ 이다. 이에 대한 프로젝터의 투사렌즈 중심간 최외각 간격(ID)은 식 (14)로부터, 각각 $0 \mathrm{~mm}, 389.95 \mathrm{~mm}, 469.45 \mathrm{~mm}$ 와 대응 된다. 따라서 다수의 광원을 사용하여 시점영상간 해상도를 증가시키는 경우, 광원 수에 따른 집속된 광폭중심간의 등간 격 조건은 인접한 시역간 크로스톡을 개선하고, 관찰자에게 자연스러운 운동시차를 제공하기 위한 필요 구속조건이 된 다. 그림 5 는 $N_{\text {views }}=1$ 일 때, 3 일 때, 5 일 때의 각각의 ID 및 최외각 광원으로부터 사영되어 집속된 광폭의 중심위치를 실험적으로 나타낸 결과이다.

\section{CONCLUSION}

본 논문을 통하여 무안경 방식의 프로젝션 3D 디스플레이 시스템에서, 광원폭의 축소에 따른 시점영상의 해상도 증가 를 검증하였다. 결론적으로 시역형성 광학계를 지나는 광원 의 폭이 좁을수록 단위 렌티릿 내에 집속 가능한 시점영상 수가 증가하며, 증가된 시점 수만큼 해상도는 배로 증가 한 
다. 25LPI의 구면 상용 렌티큐라 렌즈 시트 투과 후의 집속 된 단위화소의 광폭은 렌티큐라 렌즈 시트 투과 전의 단위화 소 광폭과 비교해 $18.7 \%$ 만큼 폭이 감소한다. 또한 해당시점 의 시역위치에 따른 Intensity gain(광폭 축소 전 광량 / 광폭 축소 후 광량)은 최대 1.76 배이다. 수치 $18.7 \%$ 는 렌티큐라 렌즈 시트 투과전의 광폭과 투과후의 축소된 광폭의 비율을 의미하며, 광폭 축소 전 보다 약 5 배 감소한 광폭에 의해 최 대 5 배 증가한 가용 광원 수를 얻을 수 있다. 이렇게 증가한 가용 광원 수로 인해 해상도를 5 배 증가 시킬 수 있다. 광원 폭의 축소를 위한 구속조건은 다음과 같다. 첫째 광원부에서 는 프로젝터로부터 사영되는 광원의 광전파특성 $M$ 의 값은 낮을 수록, 투사거리 $S_{o}$ 는 멀수록 그리고 스크린상에 결상된 단위화소의 상은 명확할수록 좋다. 둘째 렌티큐라 렌즈 부에 서는 렌티릿의 곡률반경 $R$ 이 클 수록, 분산지수 $V$ 가 작을수 록 좋다. 셋째 스크린 부에서는 확산판의 HAZE가 클수록, 광투과율이 높을수록 그리고 grain size가 작을수록 좋다. 본 논문에서 제시한 구면 렌티큐라 렌즈 시트는 상대적으로 $\mathrm{DOF}$ 범위가 비구면 렌티큐라 렌즈 시트의 DOF범위 보다 길다. 이로 인해 광축입사 혹은 비축입사 시 집속된 빔폭에 대응하는 구면 렌티큐라 렌즈 시트의 두께 허용치를 충분히 줄 수 있어 렌즈시트의 가공에 대한 공차를 크게 둘 수 있다 는 장점이 있다. 부가적으로 $\mathrm{DOF}$ 의 범위는 축소된 광폭에 비례하며, 사용하는 렌티큐라 렌즈 시트의 두께 허용치를 결 정한다. 이는 구면 형태의 상용 렌티큐라 렌즈가 갖는 구면 수차를 이용 하는 방법이며, 저가의 구면 렌티큐라 렌즈를 사용하여 고가의 비구면 렌즈를 대처할 수 있는 경제적 이점 을 갖는다. 다수의 프로젝터를 사용할 시, 증가된 프로젝터 의 대수에 비례하여 전체 해상도는 증가한다. 시스템에 사용 된 렌티릿의 피치를 기준으로 가용할 수 있는 최대 프로젝터

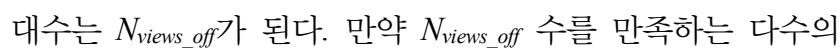
프로젝터를 사용하고, 동일한 단위화소영상을 동일 렌티릿에 사영시킬 경우, 확산판 상에 결상된 각 선광원들은 렌티릿의 피치 내에서 각기 다른 위치를 갖게 된다. 이는 해당 렌티릿
의 중심을 기준으로 수평방향의 변위 차를 나타내며, 연속된 시점분포를 위하여 각 시점영상의 광폭 중심간 변위 차는 반 드시 등간격 조건을 만족해야 한다. 일반적으로 멀티뷰 $3 \mathrm{D}$ 디스플레이에서 재생되는 영상은 2 차광학계를 지나 관찰면 에서 시점 수만큼의 시역을 형성하게 된다. 이때 관찰자가 관찰하게 되는 시점영상의 해상도는 형성되는 시역 수 즉, 시점 수에 비례하여 감소된다. 본 논문이 제시한 방법인 다 수의 광원을 이용해 동일한 영상을 등간격으로 재생시켜 디 스플레이 전체 해상도를 증가시키면, 시점 수에 비례하여 감 소되는 시점영상의 해상도를 보상하여 자연스러운 운동시차 가 가미된 선명한 입체영상을 제공할 수 있다.

\section{References}

1. N. A. Dodgson, "Autostereoscopic 3D displays," IEEE Computer Society 38, 31-36 (2005).

2. L. Kong, G. Jin, and X. Zhong, "An auto-stereoscopic projecting system based on parallax barrier and lenticular sheets," in Proc. Multimedia Technology (ICMT) (Zhejiang Braim International Hotel, China, July 2011), pp. 4-12.

3. J. Courtial, "Standard and non-standard metarefraction with confocal lenslet arrays," Opt. Commun. 282, 2634-2641 (2009).

4. E. Hecht, Optics (Addison Wesley, New York, USA, 2004), pp. 100-104.

5. J. Vasco, P. J. Bártolo, B. Silva, and C. Galo, "Laser micromachining for mould manufacturing: II. manufacture and testing of mould inserts," Assembly Automation 27, 231-239 (2007).

6. K. Roundy, "Propagation factor quantifies laser beam performance," Laser Focus World 12, 119-122 (1999).

7. T. F. Johnston Jr. and T. F. Johnston, "Beam propagation (M2) measurement made as easy as it gets: the four-cuts method," Appl. Opt. 37, 4840-4850 (1998). 